Journal of Management and Bussines (JOMB)

Volume 2, Nomor 2, Desember 2020

p-ISSN : 2656-8918

e-ISSN: $2684-8317$

DOI : https://doi.org/10.31539/jomb.v2i2.686

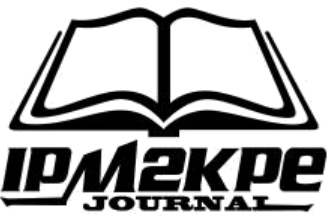

\title{
TURNOVER INTENTION (NIAT BERPINDAH) KARYAWAN BERDASARKAN LINGKUNGAN KERJA FISIK DAN LINGKUNGAN KERJA NON FISIK
}

\author{
Anisa Nur Oktaviani ${ }^{1}$, Kokom Komariah ${ }^{2}$, Dicky Jhoansyah ${ }^{3}$ \\ Universitas Muhammadiyah Sukabumi ${ }^{1,2,3}$ \\ Anisanuroktaviani@gmail.com ${ }^{1}$
}

\begin{abstract}
ABSTRAK
Tujuan penelitian ini adalah untuk mengukur pengaruh lingkungan kerja fisik dan lingkungan kerja non fisik terhadap turnover intention ( niat berpindah) karyawan pada perusahaan industri rambut palsu (wig). Metode yang digunakan dalam penelitian ini adalah metode deskriptif dan asosiatif. Populasi dalam penelitian ini adalah karyawan PT. Nina Venus Indonusa 2 Kabupaten Sukabumi. Pengambilan sampel pada penelitian ini menggunakan jenis simple random sampling yang termasuk dalam propotional sampling dengan melakukan penyebaran kuesioner sebanyak 100 kepada karyawan bagian produksi PT. Nina Venus Indonusa 2 Kabupaten Sukabumi. Hasil penelitian menunjukkan bahwa nilai $F_{\text {hitung }}$ adalah sebesar $17,350\left(>f_{\text {tabel }}=2,36\right)$ dengan signifikansi sebesar $0,000(<0,05)$. Simpulan, lingkungan kerja fisik dan lingkungan kerja fisik berpengaruh positif dan signifikan terhadap turnover intention (niat berpindah).
\end{abstract}

Kata Kunci: Lingkungan Kerja, Turnover Intention

ABSTRACT

The purpose of this study was to measure the effect of the physical work environment and the non-physical work environment on employee turnover intention in the wig industry. The method used in this research is descriptive and associative methods. The population in this study were employees of PT. Nina Venus Indonusa 2 Sukabumi Regency. Sampling in this study using simple random sampling which is included in the proportional sampling by distributing questionnaires of 100 to employees of the production division of PT. Nina Venus Indonusa 2 Sukabumi Regency. The results showed that the value of Fcount was $17.350(>$ ftabel $=2.36)$ with a significance of 0.000 (<0.05). In conclusion, physical work environment and physical work environment have a positive and significant effect on turnover intention (intention to move).

Keywords: Work Environment, Turnover Intention 


\section{PENDAHULUAN}

Sebuah perusahaan membutuhkan karyawan sebagai aset terpenting untuk mencapai kesuksesannya dalam bersaing di dunia bisnis. Sumber daya manusia merupakan penentu keberhasilan setiap organisasi, baik organisasi besar maupun kecil. Setiap organisasi membutuhkan sumber daya manusia yang memiliki kemampuan handal, memiliki rasa tanggung jawab tinggi, loyal dan memiliki daya saing global.

Robbins (2012) mengemukakan 3 alasan pentingnya manajemen sumber daya manusia bagi perusahaan. Ketiga alasan tersebut yaitu: 1) manajemen sumber daya manusia dalam perusahaan bisa menjadi sumber yang signifikan bagi keunggulan kompetitif perusahaan; 2) manajemen sumber daya manusia menjadi bagian penting dari strategi organisasi; 3) sumber daya manusia sangat mempengaruhi kinerja organisasi. Salahsatu yang menjadi masalah dalam sebuah perusahaan terutama dalam era globalisasi adalah tingkat turnover yang tinggi. Turnover dalam sebuah perusahaan adalah sebuah bentuk nyata dari permasalahan yang cukup serius yang dialami oleh suatu perusahaan. Masalah besar yang terjadi pada suatu perusahaan apabila karyawan yang terampil dan memiliki keahlian yang sangat dibutuhkan oleh perusahaan memiliki niat untuk berhenti/keluar dari perusahaan tersebut hal ini dapat membuat terganggunya kefektifitasan perusahaan.

Staffelbach (2008) mengemukakan bahwa sebuah keinginan seseorang untuk keluar dan berpindah untuk mencari pekerjaan yang lebih baik dari pekerjaan sebelumnya. Sedangkan pengertian turnover menurut Mathis \& Jackson (2011) adalah suatu niat untuk meninggalkan organisasi serta posisi pekerjaan yang dimana posisi tersebut harus digantikan oleh orang lain. Tingkat turnover yang terlampau tinggi dapat menimbulkan kerugian finansial bagi perusahaan karena perusahaan harus mengeluarkan biaya untuk melakukan perekrutan calon karyawan kembali.

Indikasi yang mempengaruhi turnover intention (niat berpindah) kayawan yang terlampau tinggi yaitu lingkungan kerja. Lingkungan kerja ada dua yaitu lingkungan kerja fisik dan lingkungan kerja nonfisik. Perusahaan harus memperhatikan lingkungan kerja yang nyaman untuk karyawannya, misalnya dalam hal penerangan di ruang kerja, sirkulasi udara, keamanan dalam melakukan pekerjaan dan suara bising. Suasana di lingkungan kerja pun sangat mempengaruhi jalannya aktivitas karyawan maka harus terciptanya hubungan yang harmonis antara karyawan dengan karyawan maupun 
karyawan dengan atasan. Apabila lingkungan kerja dirasa tidak cukup nyaman bagi karyawan maka akan karyawan akan merasa tidak betah dan ingin keluar dari perusahaan tersebut.

Berdasarkan uraian permasalahan di atas, maka peneliti tertarik untuk mengkaji pengaruh lingkungan kerja fisik dan lingkungan kerja non fisik terhadap turnover intention (niat berpindah) karyawan pada PT. Nina Venus Indonusa 2 Kabupaten Sukabumi.

\section{KAJIAN TEORI}

\section{Lingkungan Kerja Fisik}

Lingkungan kerja fisik merupakan sarana dan prasarana yang dapat dilihat dan digunakan oleh karyawan baik secara langsung maupun tidak langsung, seperti penyediaan kamar mandi, kantin dan tempat ibadah. Selain itu, menurut Soedarmayanti (2001) kondisi kerja yang juga termasuk ke dalam lingkungan kerja fisik antara lain pemilihan warna dan penerangan ruang kerja, sirkulasi udara, tingkat kebisingan, ruang gerak serta keamanan dalam melakukan pekerjaan. Namun hal tersebut dapat juga berbentuk sebuah pelayanan terhadap karyawan seperti pelayanan kesehatan dan pelayanan makanan.

Menurut Komarudin (2002) lingkungan kerja fisik adalah keseluruhan atau setiap aspek dari gejala fisik dan sosial-kultural yang mengelilingi atau mempengaruhi individu. Lingkungan kerja fisik adalah segala sesuatu yang ada di sekitar para pekerja yang dapat mempengaruhi dirinya dalam menjalankan tugas-tugas yang dibebankan, misalnya penerangan, suhu udara, ruang gerak, keamanan, kebersihan, musik dan lainlain (Nitisemito, 2002).

Usaha yang dapat dilakukan perusahaan untuk memperkecil pengaruh lingkungan kerja fisik terhadap turnover intention karyawan adalah dengan mempelajari segala hal yang berkenaan dengan sumber daya manusia, baik mengenai fisik dan tingkah lakunya yang kemudian digunakan sebagai dasar untuk mempertimbangkan lingkungan fisik yang sesuai bagi karyawannya. Menurut Soedarmayanti (2001) terdapat beberapa hal yang bisa mempengaruhi terbentuknya suatu kondisi lingkungan kerja fisik yang baik yaitu penerangan/cahaya ditempat kerja, 
sirkulasi udara ditempat kerja, keamanan ditempat kerja, peralatan dan perlengkapan kerja, kebisingan ditempat kerja serta bau tidak sedap di tempat kerja.

Berdasarkan uraian di atas peneliti dapat menyimpulkan bahwa lingkungan kerja fisik sangat berpengaruh terhadap tingkat kenyamanan karyawan dalam menjalankan pekerjaannya. Paling tidak, jika fasilitas fisik di tempat kerja mendukung maka karyawan akan merasa betah dan sangat nyaman dalam bekerja. Selain itu tidak hanya lingkungan kerja fisik, lingkungan kerja non fisik pun harus diperhatikan oleh perusahaan karena hal ini juga dapat menjadi faktor meningkatnya turnover intention jika hubungan karyawan dengan karyawan atau karyawan dengan atasan tidak baik.

\section{Lingkungan kerja non fisik}

Ruang lingkup karyawan yang berhubungan dengan perilaku antar karyawan dalam sebuah perusahaan diartikan sebagai lingkungan kerja non fisik (Wursanto, 2009). Hal tersebut menunjukkan bahwa hubungan yang bersifat hirarki antara bawahan dan atasan harus didasari dengan adanya komunikasi yang baik, sehingga segala sesuatunya akan berjalan dengan lancar sesuai aturan yang ada. Adapun menurut Umar (2008) bahwa komunikasi yang baik antara bawahan dan atasan biasanya digunakan untuk mencari dan mendapatkan informasi tentang aktivitas-aktivitas dan keputusankeputusan yang meliputi laporan pelaksanaan kerja, usulan anggaran, saran-saran yang menyangkut pelaksanaan tugas, pendapat-pendapat serta keluhan-keluhan dalam pekerjaan.

Menurut Wursanto (2009) pembentukan dan perubahan sikap serta perilaku karyawan dapat diukur dengan indikator-indikator sebagai berikut: 1) pengawasan; 2) suasana kerja; 3) sistem pemberian imbalan; 4) perlakuan baik dari sesama karyawan maupun dari atasan; 5) rasa aman dari anggota; 6) hubungan berlangsung secara serasi serta harmonis; 7) perlakuan adil serta objektif.

Berdasarkan uraian di atas peneliti dapat menyimpulkan bahwa apabila keadaan lingkungan kerja non fisik yang dirasakan oleh karyawan telah memberikan rasa nyaman, maka akan membuat karyawan tidak lagi berpikir untuk keluar dari perusahaan. Jika suatu perusahaan sudah memperbaiki dan meningkatkan keadaan lingkungan kerja menjadi lebih baik maka tingkat turnover intention karyawan akan menurun. 


\section{Turnover Intention (Niat Berpindah)}

Menurut Harnoto (2002) turnover intention adalah kadar atau intensitas dari keinginan karyawan untuk keluar dari perusahaan. Widodo (2010) menyatakan bahwa turnover intention adalah kecenderungan sikap atau tingkat dimana seorang karyawan memiliki kemungkinan untuk meninggalkan organisasi atau mengundurkan diri secara suka rela dari pekerjaannya.

Berikut adalah indikator turnover intention yang dinyatakan oleh Mobley (2011), yaitu: 1) adanya pikiran/niat untuk keluar, jika karyawan merasa mulai tidak puas dan tidak nyaman dalam melakukan pekerjaannya maka karyawan akan berpikir/berniat untuk keluar dari perusahaan tersebut; 2) adanya keinginan untuk mencari pekerjaan lain, karyawan berpikir untuk mencari pekerjaan yang dirasa lebih baik dari pekerjaan yang sedang dijalaninya; 3) niat untuk tidak berkomitmen terhadap perusahaan, karyawan tidak memiliki niat untuk bekerja di perusahaan tersebut dalam jangka waktu yang lama.

\section{METODE PENELITIAN}

Penelitian ini dilaksanakan di PT. Nina Venus Indonusa 2 Kabupaten Sukabumi. Metode penelitian yang digunakan adalah metode deskriptif dan asosiatif. Pengambilan sampel yang digunakan dalam penelitian dilakukan berdasarkan simple random sampling yang termasuk ke dalam propotional sampling dengan menyebarkan sebanyak kuesioner 100 kepada karyawan bagian produksi PT. Nina Venus Indonusa 2 Kabupaten Sukabumi.

\section{HASIL PENELITIAN}

\section{Koefesien Korelasi Ganda}

Tabel 1.

Hasil Koefisien Korelasi Ganda

\begin{tabular}{ccccc}
\hline \multicolumn{5}{c}{ Model Summary } \\
\hline Model & $\mathrm{R}$ & $\mathrm{R}$ Square & Adjusted $\mathrm{R}$ Square & Std. Error of the Estimate \\
\hline 1 & $.513^{\mathrm{a}}$ & .263 & .248 & 1.030 \\
\hline
\end{tabular}

a. Predictors: (Constant), Lingkungan Kerja Non Fisik, Lingkungan Kerja Fisik

(Sumber: Data Primer (Kuesioner), 2019)

Tabel 1 menunjukkan bahwa $\mathrm{R}$ yang diperoleh adalah sebesar 0,513. Adapun penafsiran kuat atau tidaknya koefisien korelasi ganda dapat dilihat pada tabel 2. 
Tabel 2.

Koefisien Korelasi menurut Guilford

\begin{tabular}{cc}
\hline Interval Koefisien & Tingkat Hubungan \\
\hline $0,00-0,199$ & Sangat Rendah \\
$0,20-0,399$ & Rendah \\
$0,40-0,599$ & Sedang \\
$0,60-0,799$ & Kuat \\
$0,80-1,000$ & Sangat Kuat \\
\hline
\end{tabular}

(Sumber: Sugiyono, 2014)

Berdasarkan nilai koefisien korelasi yaitu $\mathrm{R}=0,513$, maka dapat diketahui bahwa terdapat hubungan yang cukup kuat antara lingkungan kerja fisik, lingkungan kerja non fisik terhadap turnover intention (niat berpindah) karyawan.

\section{Koefisien Determinasi $\left(\mathbf{R}^{2}\right)$}

Tabel 3.

Hasil Koefisien Determinasi

\begin{tabular}{ccccc}
\hline \multicolumn{5}{c}{ Model Summary } \\
\hline Model & $\mathrm{R}$ & $\mathrm{R}$ Square & Adjusted $\mathrm{R}$ Square & Std. Error of the Estimate \\
\hline \multicolumn{1}{c}{. $^{\mathrm{a}}$} & .263 & .248 & 1.03044 \\
\hline a. & Predictors: & (Constant), Lingkungan Kerja Non Fisik, Lingkungan Kerja Fisik \\
\hline (Sumber: Data Primer (Kuesioner), 2019)
\end{tabular}

Berdasarkan hasil tabel 3, dapat diketahui bahwa nilai $\mathrm{R}^{2}$ adalah sebesar 0,263. Artinya 26,3\% variasi turnover intention karyawan dapat dijelaskan oleh variasi dari dua variabel independen yaitu lingkungan kerja fisik dan lingkungan kerja non fisik. Adapun sisanya $73,7 \%$ dipengaruhi oleh faktor lain yang tidak diteliti pada penelitian ini.

\section{Hasil Analisis Regresi Linier Berganda}

Tabel 4.

Hasil Analisis Regresi Linier Berganda

\begin{tabular}{|c|c|c|c|c|c|c|}
\hline \multicolumn{7}{|c|}{ Coefficients $^{a}$} \\
\hline & & \multicolumn{2}{|c|}{$\begin{array}{l}\text { Unstandardized } \\
\text { Coefficients }\end{array}$} & \multirow{2}{*}{$\begin{array}{c}\text { Standardized } \\
\text { Coefficients }\end{array}$} & \multirow[b]{2}{*}{$\mathrm{t}$} & \multirow[b]{2}{*}{ Sig. } \\
\hline \multicolumn{2}{|c|}{ Model } & $\mathrm{B}$ & Std. Error & & & \\
\hline \multirow[t]{3}{*}{1} & $($ Constant $)$ & 3.458 & .814 & & 4.246 & .000 \\
\hline & Lingkungan Kerja Fisik & .185 & .033 & .504 & 5.663 & .000 \\
\hline & $\begin{array}{l}\text { Lingkungan Kerja Non } \\
\text { Fisik }\end{array}$ & .016 & .035 & .041 & .464 & .644 \\
\hline & ependent Variable: Turnov & Intentic & & & & \\
\hline
\end{tabular}


Berdasarkan output regresi linier berganda pada tabel 4, maka dapat diperoleh persamaan sebagai berikut:

$Y=3,458+0,185 X_{1}+0,016 X_{2}$

\section{Uji Signifikan Secara Simultan (Uji F)}

Tabel 5.

Hasil Uji F

\begin{tabular}{llccccc}
\hline \multicolumn{7}{c}{ ANOVA $^{\mathrm{a}}$} \\
\hline \multicolumn{1}{l}{ Model } & Sum of Squares & $\mathrm{df}$ & Mean Square & \multicolumn{1}{c}{ F } & Sig. \\
\hline 1 & Regression & 36.845 & 2 & 18.423 & 17.350 & $.000^{\mathrm{b}}$ \\
& Residual & 102.995 & 97 & 1.062 & & \\
& Total & 139.840 & 99 & & & \\
\hline
\end{tabular}

a. Dependent Variable: Turnover Intention

b. Predictors: (Constant), Lingkungan Kerja Non Fisik, Lingkungan Kerja Fisik

(Sumber: Data Primer (Kuesioner), 2019)

Berdasarkan tabel 5, hasil uji F yang dilakukan menunjukkan nilai Sig. 0,000 < 0,05 dengan nilai $F_{\text {hitung }}$ sebesar 17,350 $\left(>f_{\text {tabel }}=2,36\right)$, artinya lingkungan kerja fisik dan linglungan kerja non fisik berpengaruh positif dan signifikan terhadap turnover intention (niat berpindah) karyawan.

\section{PEMBAHASAN}

Kepuasan kerja merupakan salah satu alasan terbesar yang menjadi bahan pertimbangan karyawan untuk bekerja dan bertahan dalam jangka waktu yang panjang pada satu perusahaan. Kepuasan kerja bersifat individu sehingga kepuasan kerja seorang karyawan akan berbeda dengan karyawan lainnya (Rusdianto \& Riani, 2015). Menurut Yuda \& Ardana (2017) seorang karyawan yang merasa tidak puas terhadap pekerjaannya cenderung mencari pekerjaan lain (turnover intention) dengan harapan di tempat kerja yang baru tersebut dapat memenuhi kepuasannya.

Menurut Nardiana (2014) salah satu titik terburuk bagi suatu perusahaan adalah terjadinya turnover intention yang tinggi pada perusahaanya. Dengan terjadinya turnover intention ini, dapat dikatakan bahwa perusahaan tersebut tidak mampu mengelola perilaku individu atau Sumber Daya Manusianya (SDM). Turnover yang tinggi dapat berdampak buruk bagi perusahaan karena dapat mengakibatkan ketidakstabilan dan ketidakpastian terhadap kondisi tenaga kerja yang ada serta 
tingginya biaya pengelolaan SDM seperti biaya pelatihan yang sudah dilakukan pada karyawan sampai dengan biaya rekrutmen dan pelatihan kembali (Sartika, 2014)

Salah satu hal yang paling cepat dirasakan oleh para karyawan dalam melakukan kegiatan operasional sehari-hari adalah lingkungan kerja mereka. Lingkungan kerja yang nyaman dan kondusif merupakan idaman bag setiapi karyawan sehingga karyawan dapat melaksanakan kegiatannya secara optimal, aman dan nyaman (Widhiastana et al., 2017).

Berdasarkan hasil penelitian, variabel lingkungan kerja fisik dan lingkungan kerja non fisik berpengaruh positif dan signifikan terhadap turnover intention (niat berpindah) karyawan PT. Nina Venus Indonusa 2 Kabupaten Sukabumi. Sedikit berbeda dengan yang ditemukan oleh Dwiyanto et al., (2018) bahwa terdapat pengaruh negatif yang signifikan antara lingkungan kerja dan turnover intention. Namun lebih lanjut ia menyatakan bahwa sebuah lingkungan kerja yang kondusif, baik dari dimensi fisik maupun non fisik tetap dapat mempengaruhi turnover intention.

\section{SIMPULAN}

Tiap-tiap indikator dari masing-masing variabel lingkungan kerja fisik, lingkungan kerja non fisik dan turnover intention (niat berpindah) dalam penelitian ini dapat mewakili dari masing-masing variabelnya dan sekaligus dapat dihandalkan sebagai indikator yang dapat digunakan oleh peneliti di masa mendatang.

Secara simultan, variabel lingkungan kerja fisik dan lingkungan kerja non fisik berpengaruh positif dan signifikan terhadap turnover intention (niat berpindah) karyawan PT. Nina Venus Indonusa 2 Kabupaten Sukabumi.

\section{DAFTAR PUSTAKA}

Dwiyanto, N., Sularso, R. A., \& Handriyono, H. (2018). The Influence Leadership Style, Work Environment on Turnover Intentions Through Burnout of NonPermanent Employees at Jember University. International Journal of Business and Management Invention, 7(3), 33-39

Harnoto, H. (2002). Manajemen Sumber Daya Manusia. Jakarta: Prehallindo

Komarudin, K. (2002). Dasar-Dasar Manajemen. Jakarta: Rineka Cipta

Mathis, R. L., \& Jackson, J. H. (2011). Human Resource Management. USA: SouthWestern Cengage Learning

Mobley, W. H. (2011). Pergantian Karyawan: Sebab, Akibat dan Pengendaliannya, Diterjemahkan: Nurul Iman. Jakarta: PT. Pustaka Binaman Pressindo 
Nardiana, S. (2014). Analisis Pengaruh Work Family Conflict dan Ambiguitas Peran terhadap Intention to Quit: Stres kerja sebagai Variable Intervening. Skripsi. Universitas Diponegoro

Nitisemito, A. S. (2002). Manajemen Personalia, Cetakan Ke-9, Edisi Ke-4. Jakarta: Ghalia Indonesia

Robbins, S. P. (2012) Perilaku Organisasi (15 th Edition ed.). Jakarta: PT. Indeks

Rusdiyanto, W., \& Riani, A. L. (2015). Pengaruh Kepemimpinan Transformasional dan Transaksional terhadap Kepuasan Kerja dan Organizational Citizenship Behavior. Jurnal Economia, 11(2), 161-168

Sartika, D. (2014). Pengaruh Kepuasan Kerja dan Gaya Kepemimpinan Transformasional terhadap Keinginan Keluar Karyawan dengan Komitmen Organisasi Sebagai Variabel Mediasi (Studi Kasus di CV. Putra Tama Jaya). Management Analysis Journal, 3(2), 25-34

Soedarmayanti, S. (2001). Tata Kerja dan Produktifitas Kerja: Suatu Tinjauan dari Aspek Egronomic atau Kaitan antara Manusia dengan Lingkungan Kerjanya, Cetakan Ketiga. Bandung: Mandar Maju

Staffelbach, B. (2008). Turnover Intent. Diploma Thesis. University of Zurich

Umar, H. (2008). Metodologi Penelitian untuk Skripsi dan Tesis. Jakarta: PT. Raja Grafindo Persada

Widhiastana, N. D., Wardana, M., \& Sudibya, I. G. A. (2017). Pengaruh Lingkungan Kerja dan Penghargaan terhadap Kreativitas dan Kinerja Pegawai di Universitas Pendidikan Ganesha. E-Jurnal Ekonomi dan Bisnis Universitas Udayana, 6(1), 223-250

Widodo, R. (2010). Analisis Pengaruh Keamanan Kerja dan Komitmen Organisasional terhadap Turnover Intention serta Dampaknya pada Karyawan Outsourcing. Tesis. Universitas Diponegoro

Wursanto, W. (2009). Dasar-Dasar Ilmu Organisasi. Yogyakarta: Andi

Yuda, I. B. D. P., \& Ardana, I. K. (2017). Pengaruh Kepuasan Kerja dan Stres Kerja terhadap Turnover Intention pada Karyawan Hotel Holiday Inn Express. EJurnal Manajemen Unud, 6(10), 5319-5347 